\title{
Cinema e construção cultural do espaço geográfico'
}

\author{
Maria Helena Braga e Vaz da Costa
}

1. Artigo resultante de pesquisa em andamento com apoio financeiro do CNPa.

2. Possui Pós-Doutorado (2013) em Cinema pelo International Institute - University of California at Los Angeles - UCLA (apoio financeiro CAPES), Mestrado (1993) e Doutorado (2001) em Media Studies pela University of Sussex - Inglaterra. Professora Associada II - DE do Departamento de Artes da Universidade Federal do Rio Grande do Norte - UFRN e Coordenadora do Grupo de Pesquisa Linguagens da Cena: Imagem, Cultura e Representação. Professora permanente do Programa de Pós-Graduação em Artes Cênicas. E-mail: mhcosta@ufrnet.br 


\section{Resumo}

Esse trabalho reflete sobre a noção de que as imagens cinematográficas exercem um importante papel na formação cultural do espaço geográfico. Portanto, a intenção aqui é considerar linguagem e narrativa fílmica como um importante fator na formação das experiências reais, visões, imaginações, entendimentos e percepções no contexto da produção de ambos os espaços: geográfico e fílmico.

\section{Palavras-chave}

Cinema, espaço, cultura, geografia

\section{Abstract}

This paper comments on the notion that cinematic images play a main role on the cultural formation of geographic spaces. Hence, the foremost intention is to consider film's narrative and language as a key factor in the formation of real experiences, visions, imaginations, understandings and perceptions within the context of both the geographic and filmic spaces production.

\section{Key-words}

Cinema, Space, Culture, Geography 
A imagem fabricada, controlada e distribuída pelos meios de comunicação ano 2 número 3 ocupa atualmente lugar privilegiado nas construções culturais e por esse motivo tornou-se objeto de grande interesse para a pesquisa. Sendo o cinema um desses meios producentes, controladores e distribuidores de um grande número de imagens, objetiva-se nesse artigo refletir mais especificamente sobre as imagens cinematográficas como formadoras culturais do espaço geográfico.

Existe, no contexto dos estudos e pesquisas que se interessam pela "geografia fílmica", uma perspectiva dominante: a dos Estudos Culturais (com seu background pós-estruturalista), que entende o cinema (o filme) como produtor de significados sócio-espaciais que se definem por meio da forma como estes são percebidos e vividos e também contestados e negociados através dos diversos meios (textos visuais e verbais) de produção de sentidos e significados.

Pretende-se aqui defender a idéia de uma correlação estreita entre a imagem fílmica de um determinado espaço geográfico e sua contrapartida na realidade concreta não pela via do entendimento da imagem fílmica como uma representação direta do real, mas pela via do entendimento da imagem e do espaço narrativo como elementos constituintes da própria formação, experiência e percepção do espaço geográfico real - e ainda como responsável pela construção do imaginário coletivo e cultural que substanciam e subjetivam sua existência e sua experiência.

Imagens fílmicas não simplesmente "fotografam" e "exibem" os espaços e lugares dados na realidade concreta, mas constroem o mundo (seus lugares e espaços) em termos visuais e narrativos. Atualmente devemos entender as "representações" como incluindo dois aspectos intrinsecamente interligados: por um lado, as "apresentações-interpretações", como as narrativas e as imagens fílmicas e os significados que elas constroem e produzem; por outro lado, as "imaginações" (relacionadas aos lugares e espaços imagetificados e narrados) como realidades imaginadas. Essa "metodologia" tem com certeza bases nos escritos de Roland Barthes (1982) que defende "imaginação como significação", e, portanto, nos ajuda tanto a aceitar o impacto das imagens nas realidades imaginadas, como também a entender o como e o porquê das “estratégias" imagético-urbanas. 
Para tanto, busca-se aqui demonstrar que o cinema por meio, talvez paradoxalmente e especialmente, dos filmes de ficção, com suas imagens de espaços geográficos, não serve unicamente ao propósito de observar e tornar visivelmente conhecido os espaços transitados e vividos pelo ser humano, mas em sua unidade e diversidade artística, nos auxilia na apropriação desses espaços. Podemos considerar que pela via da arte, nos permitimos perceber e conceber idéias e conceitos sobre o espaço que independem do crivo ou da relação com a realidade concreta ou menos ainda da tentativa de produção de uma verossimilhança. Como bem destaca Jean-Louis Comolli (2008, p. 180) em Ver e poder: a inocência perdida: cinema, televisão, ficção, documentário: "É como modo de inscrição maior do invisível" que o cinema privilegia o espaço.

Filmes então servem não somente como objeto para a crítica, mas como reordenamento das "imaginações geográficas" que adquirimos do mundo. Por isso mesmo é que insisto em citar David Crang (1998, p. 44) quando ele explica que: “... o conhecimento da maioria das pessoas sobre a maioria dos lugares se adquire através da mídia de vários tipos, de maneira que, para a maioria das pessoas, a representação vem antes da realidade" (tradução nossa).

Porserocinemaumaparatoenraizadonaideologia dorealismo, tradicionalmente considerado como um "meio de reprodução do real", filme teria a capacidade de estreitar as relações entre o mundo real e sua imagem produzida. No entanto, partindo do princípio que o objeto fílmico pode ser pensado independentemente da sua relação com o objeto real a ponto de fazer sentido considerá-lo como apto até mesmo a tomar o lugar do objeto - substituí-lo em nossa mente através do processo da visão, da imagem fílmica que se apresenta aos nossos olhos, uma fusão de realidade e fantasia pode ocorrer e é isto que o renomado geógrafo inglês David Harvey (1996, p. 322) presume quando afirma que "Materialidade, representação e imaginação não são mundos separados" (tradução nossa).

Existe, sem dúvida alguma, uma forte relação entre a construção fílmica da narrativa do espaço geográfico (colocando os personagens dentro de locações geográficas específicas) e o mundo real das relações sociais (CRANG, 1998; LURY e MASSEY, 1999). Mais ainda porque trazer esses espaços para o campo do visível, da imagem, representa e acarreta partilhá-los ao desvelamento de sua 
ano 2 número 3

Temáticas

livres

imagem, de seus elementos difusos ou ostensivos no que diz respeito à realidade e vivências proporcionadas pelos usuários desses mesmos espaços. O médico e etnólogo Félix-Louis Regnault, citado em Ramos e Serafim (2009, p. 90), já em 1896 constatava que "O cinema aumenta a nossa visão no tempo como o microscópio a aumenta no espaço. Ele nos permite observar fatos que escapam aos nossos sentidos porque demasiados rápidos e fugazes".

Jean-Louis Comolli (2008) defende a noção de "engodo" que segundo ele é produzido pelo aparato cinematográfico. Comolli parte do princípio de que foi o cinema o grande responsável pelo aprendizado de diversas gerações de cinéfilos que familiarizados com as imagens fílmicas produzidas no contexto do aparato cinematográfico, seus códigos e convenções narrativos, aprenderam desde cedo que "mostrar é na realidade esconder"; e ele continua: "Ver, no cinema, era ver que não se havia visto (bem), começar a ver de outra maneira. Ora, a tela não é mais uma máscara nem mesmo uma janela (Bazin): janelas e máscaras tornaram-se telas" (p. 188). Interessante é que o que torna o "engodo" verdadeiramente enganador é o fato de que por mais que tomemos consciência dele, essa consciência não o atenua. Como ainda enfatiza Comolli (2008, p. 193): “Longe de acabar com ele e de anular o seu encanto, essa consciência o garante, mais uma vez, como gozo".

Se a opinião generalizada sobre o cinema fosse de que este é muito mais um meio que "inventa" espaços e lugares, tanto quanto é da mesma forma resultante das maneiras de imaginar e pensar o espaço dado em realidade, e menos um meio de representação direta e estreita do mundo, todo e qualquer filme seria uma marca nítida de uma matriz ideológica que o conectaria com a forma de criação e produção humana inserida no contexto sócio, econômico, político e cultural e que seria identificada com facilidade no próprio espaço real sem necessariamente ser racionalizada apenas pela via da explicação da visibilidade evocada pela verossimilhança.

É preciso ressaltar que o filme, o cinema, a representação não estão fora do mundo. Não estão diante do mundo, olhando-o de fora, são eles próprios pedaços do mundo, são aquilo que do mundo se torna olhar (COMOLLI, 2008, p. 82-83). 
Contudo, mesmo sendo os filmes entendidos sob o contorno do "espelhamento do real" para não tornar essa questão mais problemática, devemos considerar a opção de não tomar a imagem fílmica de um determinado espaço geográfico como sendo tributária da linguagem do próprio espaço dizendo de si mesmo através da sua imagem. Ou seja, a imagem fílmica não pode ser avaliada como sendo a própria manifestação do espaço diante de nós por meio da sua imagem bidimensional projetada. Os caminhos da pesquisa mais promissores, tendo em vista o exposto, são aqueles que negam, antes de qualquer coisa, a ideia de representação direta, de cópia, de espelhamento, uma vez que evitam a concepção de que o espaço é uma superfície lisa, que ele é algo estático, um corte no tempo, uma simultaneidade integrada, com conexões inter-relacionadas, sem desencaixes, por onde flui um único evento, uma única história.

Em acordo com Ford (1994), em muitos casos, as cidades são percebidas e conhecidas por meio do "papel" que elas ocupam no filmes. Esse "papel" tem certamente mudado com o passar do tempo - da modernidade para a pósmodernidade, por exemplo -, e se o espaço urbano (a cidade) raramente foi filmicamente representado como apenas um background ou lugar no qual a narrativa se desenvolve, certamente este se tornou uma imagem dominante e parte constituinte da narrativa e sua significação. Desde que lugar e espaço não são backgrounds passivos - nem para qualquer tipo de encontro social, nem para representações visuais e narrativas como filmes - sua investigação deve basearse nas interações complexas entre as práticas econômicas, sociais, políticas e culturais (BAURIEDL e STRÜVER, 2011).

Faz-se necessário chamar atenção para o fato de que a área da "geografia fílmica" extrapola o contexto da análise de filmes como textos visuais e de entretenimento já que (1) entende filmes como documentos culturais que produzem (contestam) significados e (2) questiona se os efeitos produzidos pelo aparato cinematográfico são tentativas de introduzir significados subversivos ou não; o que com o tempo (re)configurariam as imagens por meio das quais os espectadores se "guiariam" no seu cotidiano urbano.

De acordo com Gillian Rose (2001) a "metodologia visual" para analisar a produção de significados deve considerar (1) a produção de uma representação, 
ano 2 número 3

Temáticas

livres

(2) a representação propriamente dita e (3) sua audiência. Esse método pode ser somado com o proposto por Hopkins (1994) que sugere que, no geral, existem três perspectivas dominantes no contexto da geografia fílmica: a geografia no filme (imagem dos espaços e lugares no filme); a geografia do filme (imaginações do espaço e lugares construídas pelas imagens fílmicas); e a geografia de filme (recepção das imaginações geográficas). Todas se baseiam e são constituídas pela ideia de que filmes tratam sobre - e brincam com - os lugares e os espaços, construindo 'novos' lugares e espaços e 'novos' significados por meio de suas construções narrativas.

Aitken e Dixon (2006) ampliam as três perspectivas mencionadas acima focando em como os significados são reconhecidos e qualificados pelas pessoas e pelos lugares por meio da sua aparência na tela, como esses significados intersectam os significados dominantes produzidos pelas diferentes mídias, e também como se dá a relação das novas tecnologias e seus efeitos na construção das imagens dos lugares e espaços bem como sua percepção.

Faz-se urgente e necessário, portanto, pensar o filme como um acontecimento resultante de articulações e desarticulações entre as multiplicidades simultâneas que coexistem em determinado lugar, e que, com suas imagens geográficas, nos apresenta e faz ver o mundo de determinada forma, sob um determinado ângulo e olhar provocando e criando um entendimento espacial particular. Segundo Renato Cunha (2009), uma "geografia criativa", - referindo-se ao conceito posto pelo cineasta russo Lev Kulechov -, aquela que desconsidera a noção de que a imagem fílmica e sua construção do espaço fílmico advêm do real, já que pode ser produto do encenar ações em locais distantes e seqüenciá-las como se fizessem parte de um único espaço, pode ser o ponto de partida para a desmistificação da idéia consensual sobre filme ser cópia, reflexo direto do real.

Sendo parte da realidade, como poderia o filme ser apenas uma cópia dela? Filmes são mais que tudo signos culturais do mundo real. Por isto a persistência na correspondência ou interligação entre a realidade espacial (aquela que existe ou, presumidamente, faz parte do mundo físico, real) e a imagem da realidade revelada através das imagens culturais que influenciam as atitudes dos elementos e objetos que interagem no mundo real. 
A paisagem cinematográfica não é, conseqüentemente, um lugar neutro para o entretenimento, ou uma documentação objetiva, ou um "espelho do real", mas uma criação cultural subjetivamente e ideologicamente comprometida, em que significados do lugar e da sociedade são formados, legitimados, contestados e as vezes esquecidos. Intervir na produção e consumo da paisagem cinematográfica nos ajuda a questionar o poder e a ideologia da representação, e a política e problemas contidos na interpretação. Isso pode, principalmente, contribuir para uma finalidade mais ampla que é mapear as geografias sociais, espaciais, e políticas do filme (HOPKINS, 1994).

Parece, portanto, que as imagens do espaço geográfico influenciam a maneira como vemos, e entendemos e como nos comportamos em seu contexto. Nesse caso, o espaço concreto também se torna um espaço que se constitui em um sistema de significação influenciado, modificado, e re-estruturado pelo cinema. Pouco a pouco, parafraseando Comolli quando ele se refere à imagem da cidade, a paisagem geográfica substitui a paisagem real, ou melhor, se torna o real de toda paisagem. Como também o geógrafo cultural Denis Cosgrove (1984, p. 1) escreveu: "a paisagem é uma maneira de ver", ou ainda "é uma maneira de fazer o mundo visível" (1984, p. 8) (tradução nossa). O cinema é simultaneamente uma maneira de ver e de criar o mundo.

Sabemos que "O cinema não filma o mundo, mas o altera em uma representação que o desloca" (COMOLLI, 2008, p. 179). Através do texto e da linguagem, o espaço fílmico auxilia na interpretação da realidade, das espacialidades presentes na realidade concreta conectando-as aos indivíduos. O espaço geográfico no filme é assim imagem e símbolo que, a um só tempo, "molda" nossa visão do mundo em geral e do espaço em particular (re)produzindo a "verdade" do lugar. Stephen Daniels e Denis Cosgrove (1988) chegam à conclusão similar no seu trabalho sobre a idéia de paisagem considerando-a uma imagem cultural que estrutura e simboliza os lugares.

Para entender uma paisagem construída ... é normalmente necessário entender as representações escritas e verbais da mesma, não como ‘ilustrações’, imagens destacadas do todo, mas como imagens constituintes 
do(s) seu(s) significado(s). E, claro, todo estudo da paisagem termina por transformar o significado, adicionando-lhe outra 'camada' de representação cultural (DANIELS e COSGROVE, 1988:1) (Tradução nossa).

Temáticas

Apesar de Daniels e Cosgrove (1988) não mencionarem o cinema, muito do seu trabalho sobre a paisagem e sua representação em textos literários pode ser aplicado aos filmes. A imagem fílmica do espaço geográfico é também uma expressão cultural. Como a paisagem é mais do que um display de uma materialidade física, mais do que uma ilustração de um lugar específico em um tempo específico, o mesmo se aplica às imagens fílmicas dos espaços geográficos.

Considere-se, por exemplo, a noção de paisagem como imagem e símbolo. Considere-se a imagem adquirida através do aparato fílmico - a imagem concebida por um meio artístico. A noção de que qualquer representação, que a arte per se "reflete" o mundo real se torna cada vez mais insólita, pois se a visão é socialmente construída e culturalmente localizada (HALL, 1997), pode-se argumentar também que não existe uma realidade a ser refletida pelos sistemas e meios imagéticos culturais.

O mundo não é pré-formado, esperando para ser 'visto’ pelo olho humano. Não há nada intrinsecamente formado, interessante, bom ou belo como nossa visão cultural dominante parece sugerir. A visão é uma prática cultural qualificada (JENKS, 1995:10) (Tradução nossa).

Mas se o filme não reflete o "real", uma realidade concreta, o que ele reflete? Coloquei (COSTA, 2002) esse mesmo questionamento em outra ocasião discutindo acerca do trabalho de Barnes e Duncan (1992) sobre os textos literários e sua argumentação sobre a noção de intertextualidade: a realidade agora pode ser considerada como um "texto", uma imagem, um conceito que define elementos concretos, mas não somente eles. O mundo "real" se torna, então, um conjunto de atos, crenças, pensamentos e imagens, que aparecem dentre outras formas de construção culturais e artísticas. O espaço é então constituído e construído por diferentes discursos que não somente dão sentido a eles mesmos, mas também interagem de uma forma tal que acabam por modificar-se e criar a "verdade" objetivada do lugar. 
Em A invenção da paisagem Anne Cauquelin (2007) chama a atenção para o fato de que no processo de visualização de um espaço/lugar, qualquer composição imagética realizada pelo artista, atribui àquilo que é representado um valor de "verdade", pois diferentemente da noção genérica de que o texto verbal (a palavra) pode mentir a imagem por sua vez parece fixar o que existe; isto é, a arte visual cristaliza a imagem no tempo e no espaço e é percebida e aceita como intrinsecamente relacionada à "verdade" do que representa. Ao invés do receptor transferir as supostas verdades do mundo físico, real, para o mundo fílmico no sentido de preencher as lacunas significativas à construção do universo ficcional, acontece o inverso: a ficção, o texto fílmico, condiciona e coordena o entendimento da imagem como verdade sobre o objeto que esta apresenta.

O cineasta explora, normalmente com detalhes, os aspectos sensíveis do objeto filmado. Interessante é perceber que filme não diz respeito somente ao visível (aquilo que é mostrado em forma de imagem), mas igualmente ao não visível - o tátil, o olfativo, o gustativo - que é também em certos casos construído e indicado pelo filme graças à relação direta existente e apreendida entre a visão e a audição propiciada pelo cinema. Exemplos óbvios são respectivamente, $A$ Partida (Yojiro Takita, 2009), Perfume ((Tom Tykwer, 2006) e A Festa de Babete (Gabriel Axel, 1987).

Nesse contexto, vale a pena citar a referência ao uso da voz-off e voz-over por Mary Ann Doane (2003, p. 462) quando ela argumenta sobre a construção pela linguagem narrativa fílmica de um "corpo fantasmático". Aquele que proporciona uma possibilidade de negar "o enquadramento como limite e uma afirmação da unidade e homogeneidade do espaço representado". A "invisibilidade" do corpo no enquadramento, relacionada à sonoridade da voz no espaço acaba determinando a construção de um espaço que contraditoriamente define-se pelo "som", não pelo visual, pela imagem do corpo humano de onde emana a voz e o espaço em que este se coloca. Claro que Doane se refere ao espaço de representação argumentando por 3 tipos de espaço que entram em jogo no cinema: (1) O espaço da diegese: sem limites físicos, espaço virtual construído pelo filme; possui particularidades audíveis e visíveis (seus objetos podem ser tocados, cheirados, degustados); (2) O espaço visível da tela (receptor da imagem): mensurável; contém os significantes visíveis; (3) O espaço acústico da sala de projeção: espaço visível que envolve o espectador. 
A voz-off no cinema narrativo clássico, insiste a autora, se configura como ano 2 número 3 ótimo exemplo no qual "os três espaços passam por elaborada superposição. Pois o fenômeno da voz-off não pode ser compreendido fora de uma consideração sobre as relações estabelecidas entre a diegese, o espaço visível da tela, e o espaço acústico da sala de projeção" (DOANE, 2003, p. 465). Assim, a voz-over (no documentário ou durante um flash-back) é de fato uma voz "descorporalizada".

O lugar onde o significante se manifesta é o espaço acústico da sala de projeção, mas este é o espaço com o qual ele menos se relaciona. A vozoff aprofunda a diegese, dá-lhe uma dimensão que excede a da imagem, e assim apóia a alegação de que existe um espaço no mundo ficcional o qual a câmera não registra. A sua própria maneira, credita espaço perdido (DOANE, 2003:465).

Esses espaços também podem ser superpostos no caso do uso cinematográfico dado a algumas imagens de determinada geografia. No caso, o reconhecimento do lugar, de um espaço geográfico específico (presente ou não na realidade concreta) pode ser construído pela narrativa e transmitido ao espectador por meio da articulação e contraposição dos três espaços citados em Doane formando assim uma imagem vivência ao mesmo tempo próxima e distante da realidade.

Concluindo, pode-se dizer que filme é um meio artístico e de comunicação intercultural e sensitivo, pois é capaz de flexibilizar e relativizar princípios que normalmente são tidos como únicos e universais e proporcionados unicamente na realidade concreta (vivida). Mas, o cinema promove e possibilita outro tipo de vivência, uma vivência de uma realidade alternativa. Nesse sentido, a imagem do espaço geográfico no filme é uma imagem cheia de significados. É uma paisagem criada por imagens "escolhidas" previamente e que, juntas, não apenas se tornam uma imagem diferente, mas também são capazes de dizer muito sobre a imagem original e/ou advindo a partir da imaginação. Sendo a imagem geográfica no filme produto da imaginação e da subjetividade de atores partícipes na concepção e realização dos dois mundos (concreto e fílmico), esta trabalha como uma "ponte" para o entendimento dos espaços e dos lugares que vivenciamos em qualquer formato. 


\section{Referências}

AITKEN, Stuart.; DIXON, Deborah. Imagining geographies of film. Erdkunde, v.60, n.4, 2006, p. 326-336.

BARNES, Trevor J.; DUNCAN, James S. Writing worlds: discourse, text \& metaphor in the representation of landscape. London: Routledge, 1992.

BARTHES, Roland. Image, music, text. London: Fontana Press, 1982.

BAURIEDL, Sybille.; STRÜVER, Anke. Strategic staging of urbanity: urban images in films and film images in Hamburg's city marketing. In: SCHMID, Heiko; SAHR, Wolf-Dietrich e URRY, John. (Eds.). Cities and fascination. Surrey: Ashgate, 2011, 169-186.

CAUQUELIN, Anne. A invenção da paisagem. São Paulo: Martins Fontes, 2007.

COMOLLI, Jean-Louis. Ver e poder: a inocência perdida: cinema, televisão, ficção, documentário. Belo Horizonte: Editora UFMG, 2008.

COSGROVE, Denis. Social formation and symbolic landscape. London: Croom Helm, 1984.

COSTA, Maria Helena Braga e Vaz da. Paisagem e simbolismo: representando e/ou vivendo o real?. Espaço e Cultura, UERJ, n.15, 2002, p. 41-50.

CRANG, Mike. Cultural geography. London: Routledge, 1998.

CUNHA, Renato. O cinema e seus outros. Brasília: LGE Editora, 2009.

DANIELS, Steven.; COSGROVE, Denis. The iconography of landscape. Cambridge: Cambridge University Press, 1988.

DOANE, M. A. A voz no cinema: a articulação de corpo e espaço. In A experiência do cinema, Xavier, I. São Paulo: Edições Graal Ltda., 2003, p. 457-475.

FORD, L. Sunshine and shadow: lighting and color in the depiction of cities in film (119-136). In AITKEN, S.; ZONN, L. (Eds.). Place, power, situation and spectacle: a geography of film. Lanham: Rowman \& Littlefield, 1994.

HALL, S. (Ed.). Representation: cultural representations and signifying practices. London: Sage Publications, 1997. 
ano 2 número 3

Temáticas

livres
HARVEY, D. Justice, nature \& the geography of difference. Oxford: Blackwell Publishers, 1996. HOPKINS, J. Mapping of cinematic places: icons, ideology, and the power of (mis)representation. In Place, power, situation and spectacle: a geography of film. AITKEN, S. C.; ZONN, L. E. (Eds.). Lanham: Rowman \& Littlefield Publishers, 1994, p. 47-65.

JENKS, C. (Ed.). Visual culture. London: Routledge, 1995.

LURY, K.; MASSEY, D. Making connections. Screen, Oxford, v.40, n.3, Autumn 1999, 229238.

RAMOS, N.; SERAFIM, J. F. Cinema e mise en scène: histórico, método e perspectivas da pesquisa intercultural". Repertório, Ano 12, n. 13, 2009, 89-97.

ROSE, G. Visual methodologies: an introduction to the interpretations of visual material. London: Sage Publications, 2001. 